\title{
Short term variations in hospital admissions and mortality and particulate air pollution
}

\author{
Jo Wordley, Sarah Walters, Jon G Ayres
}

\begin{abstract}
Objectives-To determine the presence and magnitude of any relation between short term variations in ambient concentrations of particulate matter under $10 \mu \mathrm{m}$ in diameter $\left(\mathbf{P M}_{10}\right)$ and hospital admissions and mortality in Birmingham, United Kingdom. To find the relative risk associated with various concentrations of $\mathbf{P M} M_{10}$, and to estimate the potential public health benefit of reducing $\mathbf{P M}_{10}$ to below various thresholds.

Methods-Retrospective ecological study. Air pollution data were taken from a national network monitoring station between 1 April 1992 and 31 March 1994, and weather data for the same period from the University of Birmingham Weather Service. Daily total hospital admissions for the same period for asthma, bronchitis, pneumonia, chronic obstructive pulmonary disease (COPD), acute ischaemic heart disease, acute cerebrovascular disease, all respiratory conditions, and all circulatory conditions were obtained from the West Midlands

associated with $\mathbf{P M}_{10} 24$ hours previously, and COPD deaths also with $\mathbf{P M}_{10}$ on the same day. The effect of a $10 \mu \mathrm{g} / \mathrm{m}^{3}$ rise in $\mathbf{P M}_{10}$ was estimated to represent a $2 \cdot 4 \%$ increase in respiratory admissions, a $2 \cdot 1 \%$ increase in cerebrovascular admissions, and $a 1 \cdot 1 \%$ increase in all causes mortality. In a population of 1 million, this would represent 0.5 extra respiratory admissions and 0.3 extra deaths. The increase in relative risk was linear without evidence of a threshold. The impact of reducing $\mathbf{P M}_{10}$ to below $70 \mu \mathrm{g} / \mathrm{m}^{3}$ would be small, representing less than $0 \cdot 1 \%$ of respiratory admissions and $0 \cdot 2 \%$ all causes mortality. The impact would be greater at lower thresholds.

Conclusion-Ambient outdoor concentrations of $\mathbf{P M} \mathbf{M}_{10}$ in the United Kingdom are significantly associated with several indicators of acute health effect. These associations are similar to and consistent with other studies. However, the estimated size of the public health effect is small, accounting for only a small proportion of hospital admissions and mortality over a two year period.
\end{abstract} Regional Health Authority, as well as daily total deaths from 1 April 1992 to 31 December 1994 for chronic obstructive pulmonary disease, pneumonia, all respiratory diseases, all circulatory diseases, and all causes. Multiple linear regression models were constructed after adjusting for confounding factors (day of week, month, linear trend, relative humidity, and temperature). Relative risk of admission at various thresholds of $\mathbf{P M}_{10}$ was calculated with the model, by comparing risk of admission over the threshold with mean risk of admission over the whole period. Potential public health benefits at various thresholds were calculated with the model to predict the number of admissions of deaths that could be saved if, on each day that the $\mathbf{P} \mathbf{M}_{10}$ had exceeded that threshold, it had instead been kept at the threshold level.

Results-Significant associations were found between all respiratory admissions, cerebrovascular admissions, and bronchitis admissions and $\mathbf{P} \mathbf{M}_{10}$ on the same day. Pneumonia, all respiratory admissions, and asthma admissions were significantly associated with the mean $\mathbf{P M}_{10}$ values for the past three days. Deaths from COPD, all circulatory deaths, and all causes mortality were significantly
(Occup Environ Med 1997;54:108-116)

Keywords: $\mathbf{P M}_{10}$ particles; hospital admissions; mortality

Although there is widespread concern about the potential health effects of air pollution, there is little current research from the United Kingdom to allow us to reliably estimate the public health effects of short term changes in air pollution in terms of its impact on hospital admissions and mortality. A remarkably consistent association between short term changes in mortality and particulate pollution has been found in several United States cities. ${ }^{1}{ }^{7}$ Recent reviews of the effect of particulate matter under $10 \mu \mathrm{m}$ in diameter $\left(\mathbf{P M}_{10}\right)$ on mortality suggest that a rise of $10 \mu \mathrm{g} / \mathrm{m}^{3}$ in $\mathbf{P M}_{10}$ is associated with a $1 \%$ increment in total mortality. ${ }^{89}$ Effects tend to be greater for cardiac and respiratory causes, ${ }^{58}$ to have no evident threshold, and to occur at concentrations below current ambient air quality standards.

Similar associations between $\mathbf{P M}_{10}$ and hospital admissions or emergency room attendances have also been shown in studies from North America. ${ }^{10} 16$

The net effect of a $10 \mu \mathrm{g} / \mathrm{m}^{3}$ increment in $\mathrm{PM}_{10}$ was more variable than for mortality, but 
Figure 1 Relation between hourly $P M_{10}$ measurements $\left(\mu \mathrm{g} / \mathrm{m}^{3}\right)$ at sites in Birmingham, 1 October 1993 to 31 March $1994, R=0 \cdot 36$.

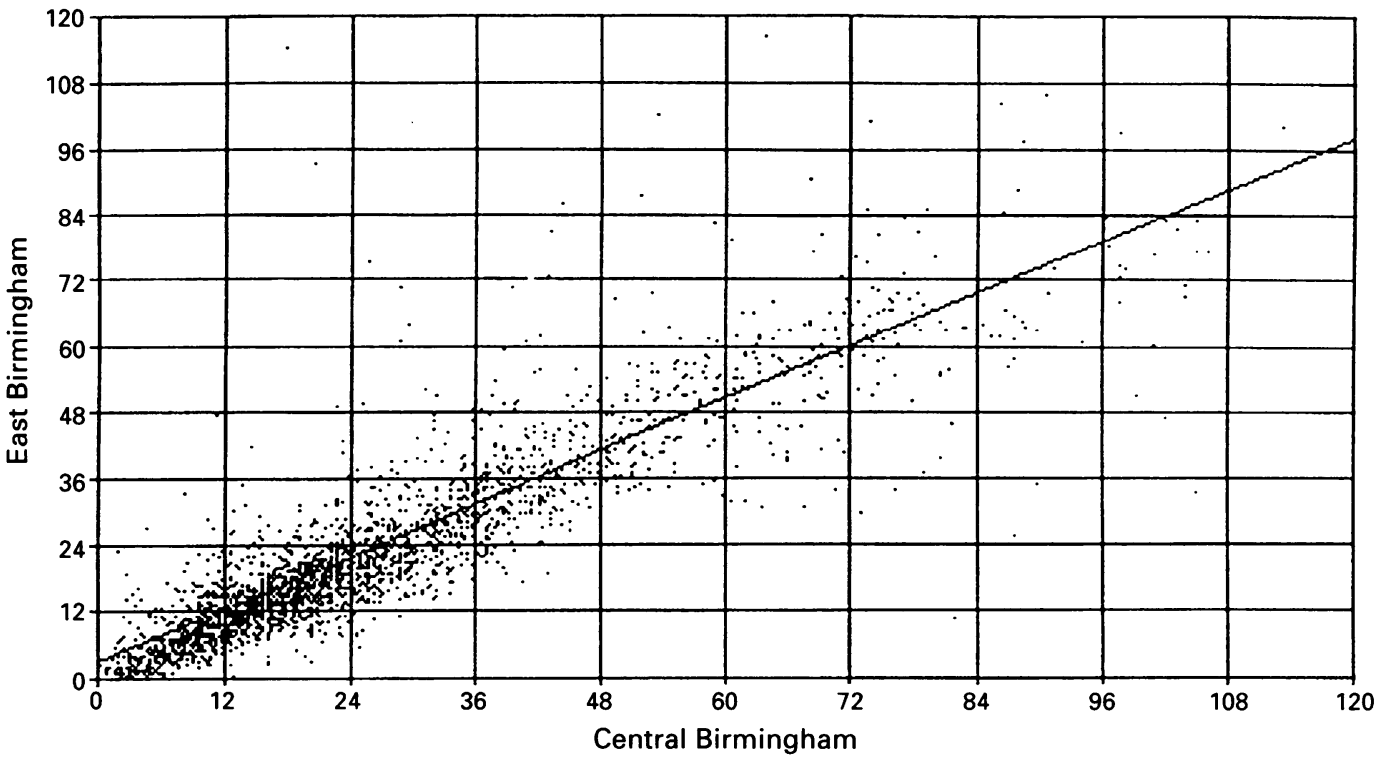

was approximately a $2 \%$ increase in admissions for respiratory disease.

There have been few published studies from Europe showing similar effects. A recent series of papers from Europe has been published considering the association between various pollutants and both mortality and hospital admissions. ${ }^{17}$ In these studies, $\mathrm{PM}_{10}$ was not considered as a measure of particulates, but two studies considered $\mathrm{PM}_{13}{ }^{1819}$ and one $\mathrm{PM}_{7}{ }^{20}$ and all three reported significant associations between both $\mathrm{SO}_{2}$ and particulates and mortality, and one also an association with hospital admissions. ${ }^{19} \mathrm{We}$ reported an association between black smoke, $\mathrm{SO}_{2}$, and hospital admissions for asthma and respiratory disease in Birmingham. However, the relation between black smoke and $\mathrm{PM}_{10}$ in urban areas is not consistent so the study could not be used to esimate the public health effects of $\mathrm{PM}_{10}$ in the United Kingdom. ${ }^{21}$ More recently, an association between mortality and black smoke was described in London, which was greatest in the warm season. ${ }^{22}$ However, no association between black smoke and hospital admissions was found in London. ${ }^{23}$ Therefore the question remains whether $\mathbf{P M}_{10}$ has similar effects in the United Kingdom to those found in North America on hospital admissions and mortality, and if so, whether there is an identifiable threshold, of particular importance when assessing an air quality standard for particulates.

This study was undertaken to find the presence and size of any association between ambient concentrations of $\mathrm{PM}_{10}$ and hospital admissions for respiratory and circulatory conditions, and cause specific and all causes mortality in Birmingham. We also set out to find the relative risk of admission or mortality when $\mathbf{P M}_{10}$ exceeds certain specific concentrations, and then to find the potential public health benefit of reducing $\mathrm{PM}_{10}$ to below these concentrations.

\section{Methods}

The chosen method was an ecological time series study that investigated hospital admissions in the residents of Birmingham (population 1 million) between 1 April 1992 and 31 March 1994, and mortality in the same population between 1 April 1992 and 31 December 1993.

\section{DATA SOURCES}

Information on hospital admissions for residents of Birmingham admitted to hospital anywhere in the West Midlands between the above dates was extracted from the West Midlands Regional Health Authority information system. Information is collected on each episode of care, and assigned back to district of residence with the postcode. The information given included date of admission and diagnostic code from the International Classification of Disease 9th Revision (ICD-9). About $10 \%$ of admissions do not have a diagnostic code assigned, but these are evenly spread through hospitals, diagnostic categories, and specialties. Information on mortality, including the date of death and ICD-9 code for underlying cause of death, was obtained from the West Midlands Regional Health Authority for residents of Birmingham who died between the dates investigated. This information is supplied to West Midlands Regional Health Authority by the Office of Population Censuses and Surveys (OPCS).

This information was broken down to produce the total daily hospital admissions in the following diagnostic categories: (a) acute bronchitis and bronchiolitis (ICD-9 code 466); (b) pneumonia (480-486); (c) asthma (493); (d) chronic obstructive pulmonary disease (COPD) (490-496 excluding 493); (e) all respiratory (total of the above, plus influenza 487); $(f)$ acute ischaemic heart disease $(410-429) ;(g)$ acute cerebrovascular disease (430-436); $(h)$ all circulatory (total of $f$ and $g$ ); (i) all causes.

Information on air quality in Birmingham for the same dates was obtained from the automated air quality monitoring station situated in a pedestrian plaza in the city centre over 50 metres from the nearest road. Data were supplied as hourly averages of $\mathrm{PM}_{10}$, ozone, CO, 
Figure 2 Plot of standardised residuals by day with all respiratory admissions as dependent variable, with a moving mean of the past three days for $P M_{i w}$. The line was fitted with the locally weighted regression smoothing with iterative weighted least squares (LOESS) method.
Figure 3 Model of predicted and observed hospital admissions for all respiratory conditions over the two year study period.

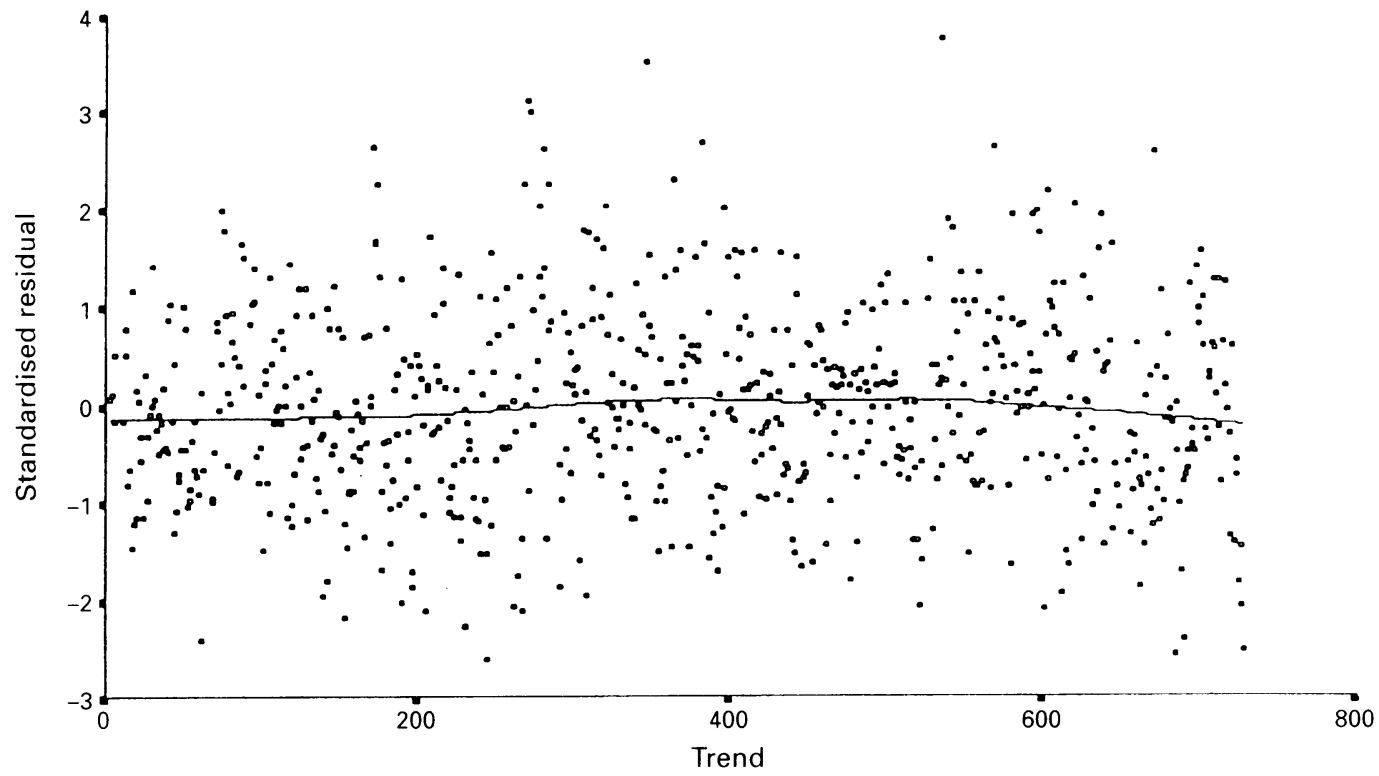

total oxides of nitrogen, $\mathrm{NO}_{2}$, and $\mathrm{SO}_{2}$, and converted to 24 hour means for analysis. This station is part of the national urban air quality monitoring network established by the Department of the Environment, and subject to strict national quality control standards. This site was the only such site operating in the West Midlands at the time of the study, although subsequent data show very close correlation with a similar site in a residential area in the east of Birmingham (fig 1). It is likely that exposure of people resident in different areas accords with their individual activity patterns, but individual exposures could not be inferred from this study. Use of the sentinel site to infer population exposure is likely to have the effect of underestimating the effect of particulate pollution on health. Meteorological information was obtained from the University of Birmingham Weather Service. This included information on temperature (24 hour mean and range), and relative humidity ( 24 hour mean and range).

DATA ANALYSIS

The distribution of admissions for acute bronchitis and pneumonia deaths was normalised by $\log$ transformation, and that of acute asthma admissions by square root transformation, to ensure that the dependent variable was normally distributed and that linear regression modelling could be applied. The potential impact of confounding factors was then assessed. For each health outcome, the mean number of events occurring on each day of the week and during each month was calculated. Data were also split into 30 ranked groups for temperature and relative humidity to determine whether the relation between these factors and each health outcome was linear or non-linear, to allow optimum modelling for these confounders in the analysis. Also, regression modelling was carried out within each of the 30 ranked temperature groups to see if the association between $\mathbf{P M}_{10}$ was constant throughout the temperature range. Daily maximum temperature showed the strongest rela-

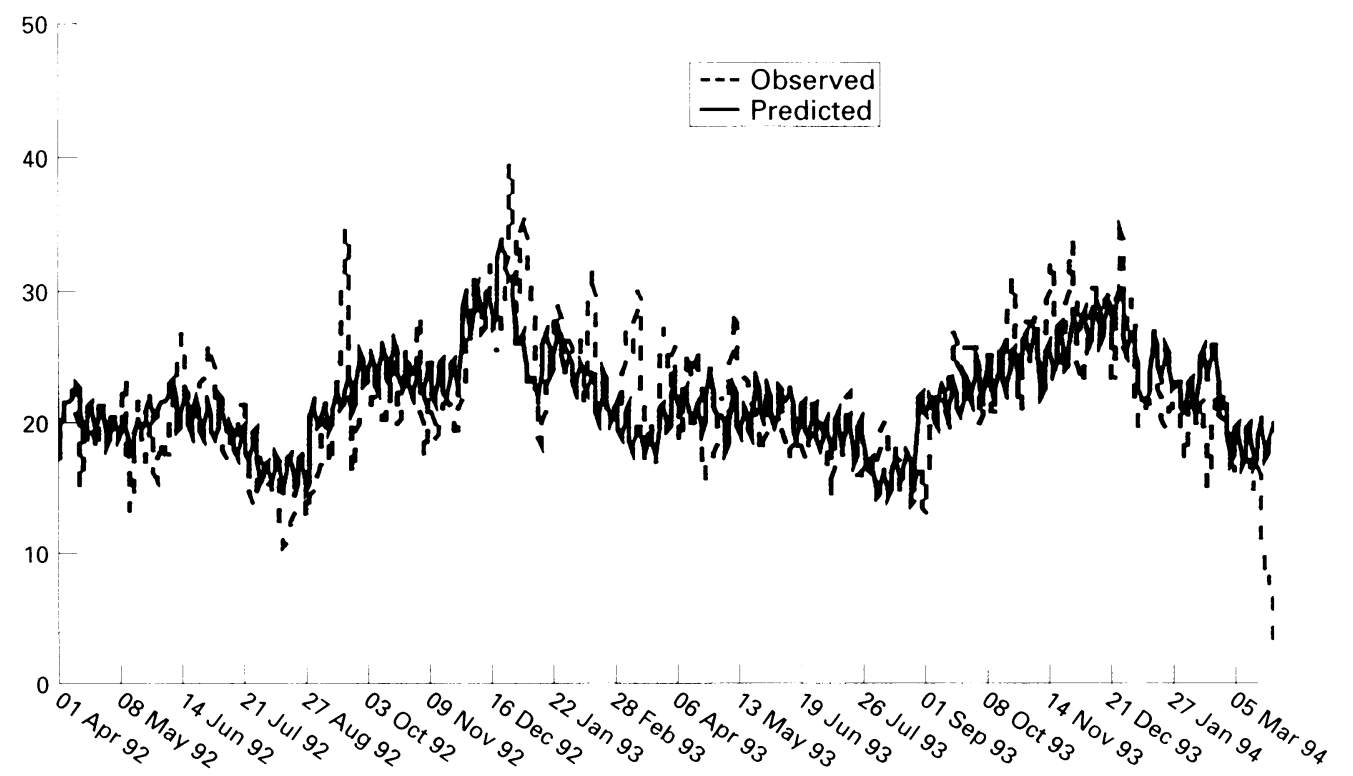


Table 1 Values of variables in multiple regression analysis

\begin{tabular}{lc}
\hline & \multicolumn{1}{c}{ Statistic } \\
Health effect indicator and $P M_{10}$ model used & Mean (range) \\
\hline Daily hospital admissions: & \\
All respiratory & $21 \cdot 8(2-49)$ \\
Asthma & $6 \cdot 2(0-21)$ \\
Bronchitis & $2 \cdot 4(0-15)$ \\
COPD & $3 \cdot 2(0-11)$ \\
Pneumonia & $3 \cdot 4(0-13)$ \\
Cerebrovascular disease & $6 \cdot 6(0-17)$ \\
Ischaemic heart disease & $25 \cdot 6(4-50)$ \\
Other & $518 \cdot 5(152-820)$ \\
Total & $587 \cdot 6(205-906)$ \\
Daily deaths: & $3 \cdot 5(0-12)$ \\
All respiratory & $11 \cdot 9(1-28)$ \\
Circulatory & $2(0-9)$ \\
Pneumonia & $1 \cdot 4(0-6)$ \\
COPD & $29 \cdot 2(9-52)$ \\
All causes & $12 \cdot 4(-2 \cdot 1-27 \cdot 4)$ \\
Daily weather: & $79 \cdot 4(51-99)$ \\
Maximum temperature $\left({ }^{\circ} \mathrm{C}\right)$ & $25 \cdot 6(2 \cdot 8-130 \cdot 9)$ \\
Mean relative humidity $\%$ & $25 \cdot 5(7 \cdot 3-104 \cdot 7)$ \\
PMio $\left(\mu \mathrm{g} / \mathrm{m}^{3}\right):$ & \\
Mean $(24$ h) & \\
Moving mean of last 3 days &
\end{tabular}

tion with health outcomes, and this relation was linear over the range of observed temperatures. The relation between health outcomes and relative humidity was also linear.

Multivariate linear regression models were then constructed for each health outcome and $\mathrm{PM}_{10}$. Day of the week and month were included as binary (dummy) variables. Maximum daily temperature was included in all models as a continuous linear variable, and mean daily relative humidity in some models where it showed a significant relation with the health outcome. Finally, a linear trend term was included in some models where it showed a signficant relation with the health outcome to adjust for long term trends in mortality. Plots of predicted versus observed values were made to assess model fit and detect residual periodic fluctuations not accounted for by the model. Also, time series plots of model residuals were made and a non-parametric smoothing technique was used to ensure that no residual seasonal fluctuations remained (fig 2).

Sensitivity analysis was carried out to ensure that the model was robust. Firstly, the effects of extremes of temperature were excluded by omitting all days exceeding the 95 th centile, or below the 5 th centile for temperature. Then days on which extremes of $\mathrm{PM}_{10}$ occurred were also excluded in the same way. A first order autoregressive term was added to the model, and a season specific effect dealt with by adding a binary variable for winter (October to March inclusive). Finally the lagged effects of temperature on two previous days together with relative humidity were included in the model.

The effect of $\mathrm{PM}_{10}$ on the same day, lagged by up to three days, and a three day mean $\mathrm{PM}_{10}$ (mean of the same day, and the two previous days) was then assessed for each health outcome. The effect of gaseous pollutants $\left(\mathrm{NO}_{2}, \mathrm{SO}_{2}\right.$, ozone) was considered in models in which significant associations between $\mathbf{P M}_{10}$ and health outcomes were found, but these did not have a significant association with health outcomes independent from that of $\mathrm{PM}_{10}$. The results presented here consider the
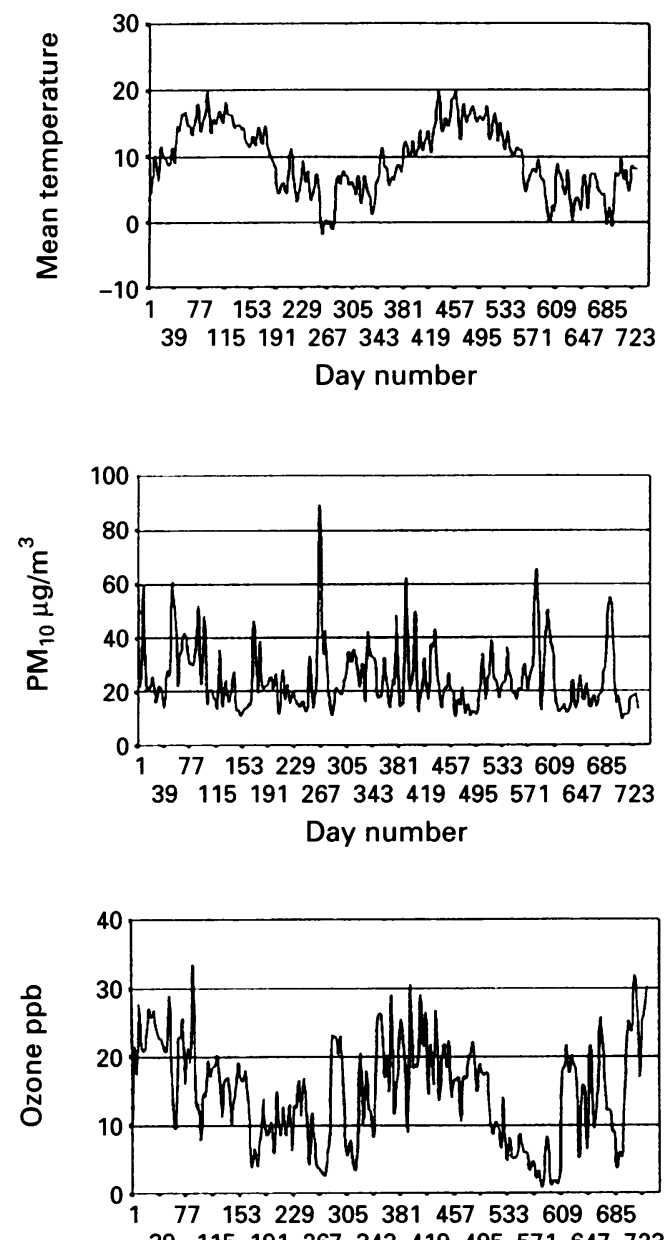

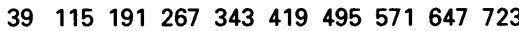

Day number

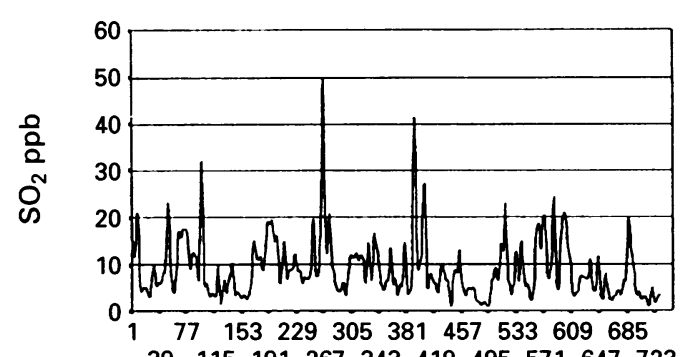

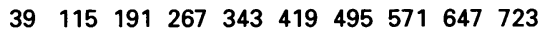

Day number

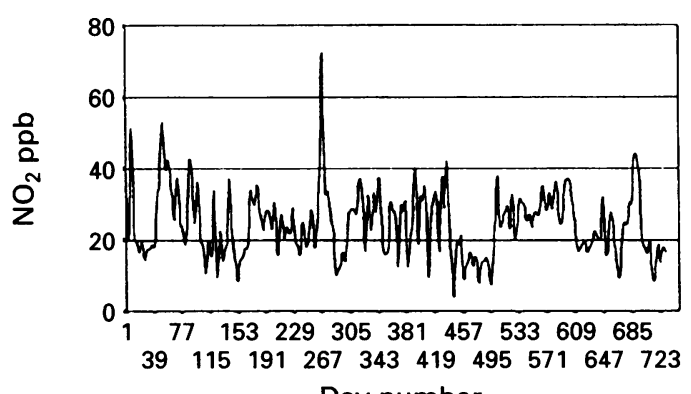

Day number

Figure 4 Plots of concentrations against time.

effect of $\mathrm{PM}_{10}$ alone. All analyses were carried out with SPSS for Windows version $6 \cdot 0$.

PROBABILITY OF OBTAINING THE RESULTS BY CHANCE

In total, 60 models were evaluated, of which 19 were significant at $P<0.05$. The probability of obtaining 19 significant results by chance is 
Table 2 Results of multiple regression analysis between PM and hospital admissions

\begin{tabular}{|c|c|c|}
\hline & Model results & \\
\hline Health affect indicator and $P M_{i}$, model used & Regression coefficint (95\%o CIs) & Pralu \\
\hline \multicolumn{3}{|l|}{ All respiratory admissions: } \\
\hline Same day $24 \mathrm{~h}^{\star}$ & $(1.0526(0.0241$ to 10.0811$)$ & 0.0003 \\
\hline I ag 1 day & $0.0404(0.017700 .0750)$ & 0.0015 \\
\hline Lag 2 day & $0.0415(0.0128$ to $(1.0701)$ & 0.00 .46 \\
\hline Lag 3 day & $0.0535(0.0249$ to 0.0820$)$ & 0.0003 \\
\hline Moving mean of past 3 days ${ }^{\star}$ & $0.0616(0.0265$ to 0.0966$)$ & $0 \cdot 0006$ \\
\hline \multicolumn{3}{|l|}{ Asthma admissions (square root): } \\
\hline Same day $24 \mathrm{~h}$ & $0.0012(0.0018000 .0041)$ & (1).4391 \\
\hline Iag 1 dav & $0.0027-0.0002$ to 0.0057 & 0.072 \\
\hline Lag 2 day $^{\star}$ & 0.00380 .0009 to $(1.0068)$ & $(1.0112$ \\
\hline I ag 3 day & $0.0036(0.0007$ to 0.0066$)$ & $(1.015$ \\
\hline Moving mean of past 3 days* & $0.004600 .0010000 .0081)$ & 0.012 \\
\hline \multicolumn{3}{|l|}{ Bronchitis admissions $(\log )$ : } \\
\hline Same day $24 \mathrm{~h}^{\star}$ & $0.00)(0.0007[00.00(134)$ & 0.0033 \\
\hline Lag 1 day & $0.001-0.0004000 .0024$ & 0.1536 \\
\hline Lag 2 day & $(1.001(-0.000+100.0024)$ & 0.1519 \\
\hline Lag 3 day & $5 \cdot 10 \quad-0.001+10(1.0015$ & $(1.9392$ \\
\hline Moving mean of past 3 days & $0.001,0.0007$ to 0.0027$)$ & 0.2319 \\
\hline \multicolumn{3}{|l|}{ Pneumonia admissions: } \\
\hline Same day $24 \mathrm{~h}$ & $0.0167(0.0051$ to 0.0008$)$ & $(1.001$ \\
\hline Lag 1 day & $0.0104(0.0005$ to $(0.0204)$ & 0.0393 \\
\hline Iag 2 day & $0.0145(0.0046$ to 0.0244$)$ & 0.0041 \\
\hline Lag 3 day* & $0.0187(0.0089$ to 0.0286$)$ & 0.0002 \\
\hline Moving mean of past 3 davs ${ }^{\star}$ & $0.02050 .008+$ to 0.0625 & 0.00009 \\
\hline \multicolumn{3}{|l|}{ COPD admissions: } \\
\hline Same day $24 \mathrm{~h}$ & $0.0023(-0.0069$ to 0.0115$)$ & 0.618 \\
\hline Lag 1 day & $0.0072(0.0020000 .0164$ & 0.1251 \\
\hline I ag 2 dav & $0.002(0.0072$ to 0.0112$)$ & 0.6698 \\
\hline Lag 3 day & $0.0(15)(0.0042$ to $(1.0142)$ & 0.2873 \\
\hline Moving mean of past 3 days & $0.0056)-0.0055$ to 0.0168 & 0.3219 \\
\hline \multicolumn{3}{|l|}{ Cerebrovascular disease admissions: } \\
\hline Same day $24 \mathrm{~h}^{\star}$ & $0.0137,0.00012$ to $(1.0273$ & 0.0475 \\
\hline Lag 1 dav & $0.00997 \quad 0.0039 t 0(0.0233)$ & 0.1603 \\
\hline Lag 2 day & $0.0031(-0.0104$ to 0.0167$)$ & 0.6494 \\
\hline Lag 3 day & $0.0072-0.0063 t 00.0207$ & $(1.2975$ \\
\hline Moving mean of past 3 days & $0.011, \quad 0.005400 .0274)$ & $(1.1899$ \\
\hline \multicolumn{3}{|l|}{ Ischaemic heart disease admissions: } \\
\hline Same day $24 \mathrm{~h}$ & $0.0074(0.0122+000.0371)$ & 0.627 \\
\hline Lag 1 day & $0.0069(-0.0364$ to 0.0229$)$ & 0.6536 \\
\hline Lag 2 day & $0.0179(-0.047600 .0119)$ & (1) 2384 \\
\hline Lag 3 day & $0.0042 \quad(0.0341 \mathrm{t} 00.0256)$ & 0.7811 \\
\hline Moving mean of past 3 days & $0.0177: 0.0538$ to 0.0184 & (1). 3354 \\
\hline
\end{tabular}

*Model chosen for further analysis

Table 3 Results of multiple regression analysis between PM and mortality.

$$
\text { Hodel rivults }
$$

\begin{tabular}{|c|c|c|}
\hline Health offect indicator und $P M_{B}$ model used & Regression codficitit $(95 \%$ CIs) & Pialu \\
\hline \multicolumn{3}{|l|}{ All respiratory deaths: } \\
\hline Same day $24 \mathrm{~h}$ & $-0.002(-0.0127600 .0087)$ & (1).7133 \\
\hline Lag 1 day & $0.0061 \quad 0.0046$ to 0.0168$)$ & 0.2621 \\
\hline Lag 2 day & $0.0086(-0.0020$ to 0.0193$)$ & 0.1126 \\
\hline Lag 3 day & $0.0046(-0.0061$ to 0.0152$)$ & 0.4021 \\
\hline Moving mean of past 3 days & $0.0098(-0.0032$ to 0.0228$)$ & (0. 1407 \\
\hline \multicolumn{3}{|l|}{ All circulatory deaths: } \\
\hline Same day $24 \mathrm{~h}$ & $(1.00060(\cdots 0.011+t 00.0246)$ & 0.4701 \\
\hline Lag 1 day* & $(1.0198(0.0017$ to 0.0380$)$ & 0.0302 \\
\hline Lag 2 day & $0.0093(-0.0087$ to 0.0274$)$ & $(1.311$ \\
\hline Lag 3 day & $0.006(-0.0122$ to 0.0241$)$ & 0.5206 \\
\hline Moving mean of past 3 days & $0.0149(-0.0072$ to $(0.0371)$ & $(1 \cdot 1864$ \\
\hline \multicolumn{3}{|l|}{ COPD deaths: } \\
\hline Same day $24 \mathrm{~h}^{\star}$ & $0.0069(0.0010$ to $(0.0127)$ & 0.021 \\
\hline Lag 1 day ${ }^{*}$ & $0.0065(0.0007$ to 0.0123$)$ & 0.287 \\
\hline Lag 2 day & $(1.001138(0.0020$ to $(0.0097)$ & $(0.1976$ \\
\hline Lag 3 day & $0.0016(-0.0043$ to 0.0075$)$ & 0.5978 \\
\hline Moving mean of past 3 days & $(1.0055(-0.0016$ to 0.0126$)$ & 0.131 \\
\hline \multicolumn{3}{|l|}{ Pneumonia deaths $(\log )$ : } \\
\hline Same day $24 \mathrm{~h}$ & $-0.0013(-0.0029$ to 0.0003$)$ & 01092 \\
\hline Lag 1 day & $6 \times 10 \quad-0.0016 t 00.0015)$ & 0.9401 \\
\hline Lag 2 day & $0.0009(-0.0006$ to 0.0023$)$ & 0.2635 \\
\hline Lag 3 day & $0.0002-0.0012100 .0017$ & (1).7741 \\
\hline Moving mean of past 3 days & $0.0008: 0.0011$ to 0.0026 & $(0.4172$ \\
\hline \multicolumn{3}{|l|}{ All causes deaths: } \\
\hline Same day $24 \mathrm{~h}$ & $0.0075(-0.0370100 .0219)$ & (1).6157 \\
\hline Lag 1 day* & $0.032(-0.0026$ to $(0.0614)$ & 0.033 \\
\hline I.ag 2 day & $0.0085(-0.0209$ to 0.0378$)$ & 0.5716 \\
\hline Lag 3 day & $0.0022(0.0273$ to 0.0317$)$ & $(0.8836$ \\
\hline Moving mean of past 3 days & $0.0186(0.0174$ to 0.0546$)$ & 0.3094 \\
\hline
\end{tabular}

* Model chosen for further analysis.

$0 \cdot 16$. Ten models were significant at $\mathrm{P}<0.01$. The probability of obtaining this result by chance is 0.06 .

Of the models constructed for each of the 30 ranked temperature groups, 17 were significant at the $1 \%$ level and 26 at the $5 \%$ level. The probabilities of these results occurring by chance are 0.0176 and 0.057 respectively.
MODELLING PUBLIC HEALTH EFFECTS

Previous studies have not been able to show a threshold effect for $\mathrm{PM}_{1 \ldots}$. We calculated the relative risk of hospital admission or death for each outcome by comparing the risk on days when $P M_{1,}$ particles exceeded 50, 60, and 70 $\mu \mathrm{g} / \mathrm{m}$ with the mean risk over the whole two year period. The estimates of risk were made with the model to adjust for confounding factors. This would allow us to see at what level the relative risk rose significantly above 1 .

We also used the model to estimate the number of health events that could be saved for each outcome if the 24 hour mean $\mathrm{PM}_{4}$. had been kept below 50, 60, and $70 \mu \mathrm{g} / \mathrm{m}^{3}$ over the two year period. Each threshold was looked at in turn. On days on which the threshold was exceeded in Birmingham, the difference between the observed concentration and the threshold was multiplied by the regression coefficient for the relevant model to estimate the number of health events that could have been saved on that day. These were then added together for the whole period to estimate total health events saved. If measures were taken to reduce $\mathrm{PM}_{1 "}$ to below 70 $\mu \mathrm{g} / \mathrm{m}$, then it is likely that the number of days when $\mathrm{PM}_{1 .}$ particles exceeded 50 and 60 $\mu \mathrm{g} / \mathrm{m}$ would fall, and possibly the mean value. Our estimates do not take account of this, and represent conservative estimates of health benefit.

To allow comparison with previous publications, present results were also calculated as a percentage increase in health outcome for a $10 \mu \mathrm{g} / \mathrm{m}^{i}$ increment in $\mathrm{PM}_{1,}$.

\section{Results}

Figure 3 is a plot of predicted and actual measurements to show an example of model fit for all respiratory admissions with a three day moving average model for $\mathrm{PM}_{1 \ldots}$.

Table 1 shows the distribution of variables used in the analyses. Data were missing for 11 out of a total of 730 days. Mean 24 hour $\mathrm{PM}_{1}$ exceeded $70 \mu \mathrm{g} / \mathrm{m}^{3}$ on 13 days, $60 \mu \mathrm{g} / \mathrm{m}^{3}$ on 27 days, and $50 \mu \mathrm{g} / \mathrm{m}^{3}$ on 60 days. Figure 4 shows plots of time against temperature, $\mathrm{PM}_{\mathfrak{l}}$, ozone, $\mathrm{NO}_{2}$, and $\mathrm{SO}_{2}$.

Table 2 shows the results of multiple regression analysis for hospital admissions, and table 3 shows the results for deaths. Hospital admissions for chronic obstructive pulmonary disease (COPD) and ischaemic heart disease did not show any significant association with $\mathrm{PM}_{11}$ with any lag. Hospital admissions for asthma, bronchitis, all respiratory disease, and pneumonia all showed significant associations with

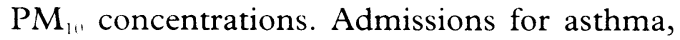
respiratory disease, and pneumonia showed steeper gradients for the three day moving average $\mathrm{PM}_{11}$, although significant associations were also found at varying degrees of lag for these health outcomes. Bronchitis and acute cerebrovasular admissions showed significant associations only for $\mathbf{P M}_{10}$ of the same day.

Associations between mortality and ambient $\mathrm{PM}_{1}$ were of lower significance than those for hospital admissions. All causes mortality 
Table 4 Regression analysis for relation between $P M_{10}$ and hospital admissions for all respiratory disease (same day) in each of 30 ranked groups of temperature (models include adjustment for weekday)

\begin{tabular}{|c|c|c|c|c|}
\hline $\begin{array}{l}\text { Temperature } \\
\text { group }\end{array}$ & $\begin{array}{l}\text { Temperature } \\
\text { (mean (range)) }\end{array}$ & $x$ coefficient & SEM & Pvalue \\
\hline 1 & $-1.39(-2.8$ to 0.8$)$ & 0.1598 & 0.0976 & $0 \cdot 126$ \\
\hline 2 & $0.78(0.1$ to 1.58$)$ & 0.2301 & 0.0826 & 0.0127 \\
\hline 3 & $2 \cdot 18(1.6$ to 2.9$)$ & 0.3503 & 0.089 & 0.0011 \\
\hline 4 & $3.35(2.9$ to 3.8$)$ & $0 \cdot 1878$ & $0 \cdot 1729$ & $0 \cdot 2925$ \\
\hline 5 & 4.05 (3.8 to 4.3$)$ & 0.8589 & $0 \cdot 2491$ & 0.0029 \\
\hline 6 & $4.65(4.3$ to 4.9$)$ & 0.6589 & 0.1452 & 0.0003 \\
\hline 7 & $5 \cdot 20(4.9$ to 5.5$)$ & $0 \cdot 1441$ & $0 \cdot 1975$ & 0.4761 \\
\hline 8 & $5.73(5.5$ to 6.0$)$ & 0.8529 & $0 \cdot 1481$ & $<0.0001$ \\
\hline 9 & $6 \cdot 24(6 \cdot 1$ to $6 \cdot 4)$ & 0.8258 & $0 \cdot 1586$ & 0.0001 \\
\hline 10 & $6.66(6.4$ to 6.9$)$ & 0.3327 & $0 \cdot 1091$ & 0.0069 \\
\hline \multicolumn{2}{|c|}{ Mean $\mathrm{x}$ coefficient rank $1-10$} & 0.4601 & & \\
\hline 11 & $7.08(6.9$ to 7.3$)$ & 0.4348 & $0 \cdot 1552$ & 0.0134 \\
\hline 12 & $7 \cdot 57(7 \cdot 3$ to $7 \cdot 9)$ & 0.5506 & $0 \cdot 1941$ & 0.0109 \\
\hline 13 & $8.16(7.9$ to 8.5$)$ & 0.2743 & $0 \cdot 1117$ & 0.0251 \\
\hline 14 & $8 \cdot 80(8.5$ to $9 \cdot 1)$ & 0.6696 & 0.0923 & $<0.0001$ \\
\hline 15 & $9.36(9.1$ to 9.6$)$ & 0.3805 & $0 \cdot 1019$ & 0.0015 \\
\hline 16 & $9.90(9.6$ to $10 \cdot 3)$ & 0.4982 & 0.1036 & 0.0002 \\
\hline 17 & $10.6(10.3$ to 10.9$)$ & $0 \cdot 361$ & 0.0917 & 0.004 \\
\hline 18 & $11 \cdot 1(10.9$ to 11.3$)$ & 0.4042 & $0 \cdot 1075$ & 0.0014 \\
\hline 19 & $11.4(11.3$ to 11.7$)$ & $0 \cdot 2475$ & $0 \cdot 126$ & 0.0671 \\
\hline 20 & $11.9(11.8$ to 12.1$)$ & 0.2655 & 0.0955 & 0.0123 \\
\hline \multicolumn{2}{|c|}{ Mean $x$ coefficient rank $11-20$} & 0.4083 & & \\
\hline 21 & $12 \cdot 6(12 \cdot 1$ to $13 \cdot 1)$ & 0.5448 & $0 \cdot 1258$ & 0.0005 \\
\hline 22 & $13.5(13.1$ to 13.8$)$ & 0.4615 & 0.0979 & 0.0002 \\
\hline 23 & $14.1(13.8$ to 14.3$)$ & 0.359 & 0.0932 & 0.0002 \\
\hline 24 & $14 \cdot 6(14 \cdot 3$ to $14 \cdot 8)$ & 0.0204 & 0.1355 & $0 \cdot 8871$ \\
\hline 25 & $15.0(14.8$ to $15 \cdot 3)$ & 0.3334 & $0 \cdot 1166$ & 0.0109 \\
\hline 26 & $15.6(15.3$ to 15.9$)$ & $0 \cdot 2031$ & 0.0932 & 0.0457 \\
\hline 27 & $16 \cdot 1(15.9$ to 16.5$)$ & 0.3787 & 0.0796 & 0.0002 \\
\hline 28 & $16.9(16.5$ to 17.3$)$ & 0.4082 & $0 \cdot 1056$ & 0.0011 \\
\hline 29 & $17 \cdot 8(17 \cdot 3$ to $18 \cdot 4)$ & 0.2578 & 0.0991 & 0.0186 \\
\hline \multirow{3}{*}{\multicolumn{2}{|c|}{$\begin{array}{l}\text { Mean x coefficient rank } 21-30 \\
\text { Overall mean x coefficient }\end{array}$}} & 0.2979 & 0.0538 & $<0.0001$ \\
\hline & & 0.3265 & & \\
\hline & & 0.3984 & & \\
\hline
\end{tabular}

Table 5 Results of sensitivity analysis of model for same day $24 \mathrm{hPM} \mathrm{PM}_{10}$ and hospital admissions for all respiratory conditions, showing effects of censoring

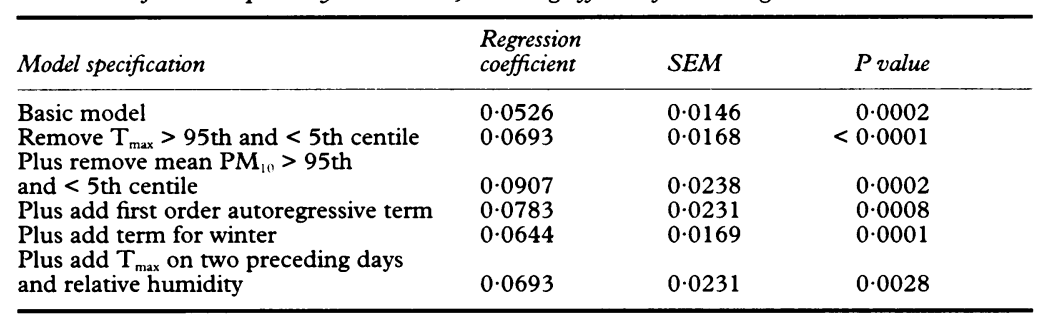

Table 6 Percentage and absolute increase in health effects for a $10 \mu \mathrm{g} / \mathrm{m}^{3}$ change in $P M_{10}$ for different health outcomes and $P M_{10}$ models

\begin{tabular}{|c|c|c|c|}
\hline $\begin{array}{l}\text { Health effect indicator and } P M_{10} \\
\text { model used }\end{array}$ & $\begin{array}{l}\text { Mean daily } \\
\text { events }\end{array}$ & $\begin{array}{l}\text { \% Increase in } \\
\text { daily events } \\
(95 \% \mathrm{CI})\end{array}$ & $\begin{array}{l}\text { Absolute increase } \\
\text { in daily events } \\
(95 \% \mathrm{CI})\end{array}$ \\
\hline All respiratory admissions: & $21 \cdot 8$ & & \\
\hline Same day & & $2 \cdot 4(1 \cdot 1$ to $3 \cdot 7)$ & $0.53(0.24$ to 0.81$)$ \\
\hline $\begin{array}{l}\text { Moving mean of past } 3 \text { days } \\
\text { Asthma admissions: }\end{array}$ & $6 \cdot 2$ & & $0.62(0.27$ to 0.97$)$ \\
\hline Lag 2 day & & $3.3(0.7$ to $6 \cdot 2)$ & $0.2(0.05$ to 0.39$)$ \\
\hline Moving mean of past 3 days & & $4.0(0.8$ to $7 \cdot 6)$ & $0.25(0.05$ to 0.47$)$ \\
\hline Bronchitis admissions: & $2 \cdot 4$ & & \\
\hline Same day & & $5.8(1.7$ to 11.9$)$ & $0.14(0.04$ to 0.29$)$ \\
\hline Pneumonia admissions: & $3 \cdot 4$ & & \\
\hline $\begin{array}{l}\text { Lag } 3 \text { day } \\
\text { Moving mean of past } 3 \text { days }\end{array}$ & & $\begin{array}{l}5.7(2.7 \text { to } 8.5) \\
6.3(2.5 \text { to } 9.7)\end{array}$ & $\begin{array}{l}0.19(0.09 \text { to } 0.29) \\
0.21(0.04 \text { to } 0.29)\end{array}$ \\
\hline Cerebrovascular admissions: & $6 \cdot 6$ & & \\
\hline Same day & & $2 \cdot 1(0.03$ to $4 \cdot 1)$ & $0.14(0.002$ to 0.27$)$ \\
\hline $\begin{array}{l}\text { Circulatory deaths: } \\
\text { Lag } 1 \text { day }\end{array}$ & 11.9 & $1.7(0.2$ to 3.2$)$ & $0.20(0.02$ to 0.38$)$ \\
\hline COPD deaths: & $1 \cdot 4$ & & \\
\hline Same day & & $5 \cdot 0(0 \cdot 7$ to $9 \cdot 3)$ & $0.07(0.01$ to 0.13$)$ \\
\hline Lag 1 day & & $5 \cdot 0(0.5$ to $8 \cdot 6)$ & $0.07(0.007$ to 0.12$)$ \\
\hline $\begin{array}{l}\text { All causes mortality: } \\
\text { Lag } 1 \text { day }\end{array}$ & $29 \cdot 2$ & $1,(0.1$ to 2,1$)$ & \\
\hline Lag 1 day & & $1 \cdot 1(0 \cdot 1$ to $2 \cdot 1)$ & $0.32(0.026$ to 0.61$)$ \\
\hline
\end{tabular}

and all deaths from circulatory causes and COPD were significantly associated with $\mathrm{PM}_{10}$ lagged by one day, and COPD was significantly associated with same day $\mathrm{PM}_{10}$. All respiratory deaths and deaths from pneumonia were not significantly associated with $\mathrm{PM}_{10}$. No other significant associations between mortality and $\mathrm{PM}_{10}$ were found.

Table 4 shows the results of applying a model for all respiratory admissions within 30 ranked groups of temperature, adjusted for day of the week. This shows that in 17 of the 30 models, $\mathrm{PM}_{10}$ was significantly associated with hospital admissions for respiratory disease at the $1 \%$ level, and in 26 models at the $5 \%$ level. The regression coefficient was marginally larger for the coolest tertile. This confirms that the association found in the regression models seems to occur throughout the temperature range.

Table 5 shows the results of sensitivity analysis for the association between same day 24 hour $\mathrm{PM}_{10}$ and hospital admissions for all respiratory conditions.

Table 6 shows the percentage and absolute increases in health outcomes for a $10 \mu \mathrm{g} / \mathrm{m}^{3}$ change in $\mathrm{PM}_{10}$. This study estimated that for a $10 \mu \mathrm{g} / \mathrm{m}^{3}$ change in $\mathrm{PM}_{10}$, there would be a $2.4 \%$ increase in respiratory admissions, a $2.1 \%$ increase in cerebrovascular admissions, a $1.7 \%$ increase in circulatory mortality, and a $1 \cdot 1 \%$ increase in all causes mortality.

Table 7 shows the relative risk associated with changes of $\mathrm{PM}_{10}$ above certain specific thresholds. Figures 5 and 6 show examples of the calculated increment in relative risk seen at different thresholds. The increase in risk is almost linear with no evidence of threshold.

Table 8 shows the number and percentage of hospital admissions that might be avoided if $\mathrm{PM}_{10}$ values were limited to certain thresholds. Keeping $\mathrm{PM}_{10}$ below $70 \mu \mathrm{g} / \mathrm{m}^{3}$ would reduce all health outcomes by under $1 \%$, and total mortality by only $0 \cdot 2 \%$. The potential number of admissions or deaths saved increase at lower thresholds.

\section{Discussion}

This study has shown for the first time an association between current ambient concentrations of $\mathrm{PM}_{10}$ and short term variations in hospital admissions and mortality in the United Kingdom. The question remains as to whether the association found is causal, or due to residual confounding. The models used in this study considered obvious causes of confounding, including meteorological factors and periodic fluctuations in hospital admissions and mortality associated with health service administrative factors, seasonality, and long term trends. In this, it is similar to other modelling exercises. However, data were not available for other potential confounding factors, in particular the daily incidence of respiratory viral infections and pollen count, and these could represent residual sources of confounding. Indeed, divergences between the predicted and actual admissions were seen at times of year when there is likely to be a high incidence of respiratory viral infections. It is possible that residual confounding may equally reduce, as well as increase the strength of association.

Another possible area for confounding to occur is in the treatment of meteorological factors. Our analysis, in common with others, used same day 24 hour maximum temperature and mean relative humidity. Also, we consider 
Table 7 Relative risk of different health outcomes when $P M_{10}$ exceeds different thresholds

\begin{tabular}{|c|c|c|c|}
\hline $\begin{array}{l}\text { Health outcome indicator and } P M_{t o} \\
\text { model used }\end{array}$ & $\begin{array}{l}\text { Threshold at } \\
50 \mu g / m^{3} \\
R R(95 \% C I)\end{array}$ & $\begin{array}{l}\text { Threshold at } \\
60 \mu g / m^{3} \\
R R(95 \% \text { CI })\end{array}$ & $\begin{array}{l}\text { Threshold at } \\
70 \mu g / m^{3} \\
R R(95 \% \text { CI })\end{array}$ \\
\hline \multicolumn{4}{|l|}{ All respiratory admissions: } \\
\hline $\begin{array}{l}\text { Same day } \\
\text { Moving mean of past } 3 \text { davs }\end{array}$ & $1 \cdot 15(1.05$ to $1 \cdot 24)$ & $1.20(1.09$ to 1.30$)$ & $1.31(1.20$ to 1.42$)$ \\
\hline $\begin{array}{l}\text { Moving mean of past } 3 \text { days } \\
\text { Asthma admissions: }\end{array}$ & $1 \cdot 12(1.01$ to $1 \cdot 22)$ & $1.15(1.03$ to 1.26$)$ & \\
\hline \multicolumn{4}{|l|}{ Asthma admissions: } \\
\hline $\begin{array}{l}\text { Lag } 2 \text { day } \\
\text { Moving mean of past } 3 \text { days }\end{array}$ & $\begin{array}{l}1.05(0.88 \text { to } 1.23) \\
1.07(0.88 \text { to } 1.27)\end{array}$ & $\begin{array}{l}1.03(0.86 \text { to } 1.21) \\
1.15(0.92 \text { to } 1.35)\end{array}$ & $1.12(0.93$ to 1.32$)$ \\
\hline \multicolumn{4}{|l|}{ Bronchitis admissions: } \\
\hline Same day & $1 \cdot 18(0 \cdot 89$ to $1 \cdot 44)$ & $1.46(1.04$ to 1.73$)$ & $1 \cdot 77(1 \cdot 21$ to $2 \cdot 11)$ \\
\hline \multicolumn{4}{|l|}{ Pneumonia admissions: } \\
\hline $\begin{array}{l}\text { Lag } 3 \text { day } \\
\text { Moving mean of past } 3 \text { days }\end{array}$ & $\begin{array}{l}1.11(0.91 \text { to } 1.31) \\
1.30(1.07 \text { to } 1.53)\end{array}$ & $\begin{array}{l}1.25(1.04 \text { to } 1.45) \\
1.43(1.18 \text { to } 1.68)\end{array}$ & $1.39(1.18$ to 1.60$)$ \\
\hline \multicolumn{4}{|l|}{ Cerebrovascular admissions: } \\
\hline Same day & $1 \cdot 16(1 \cdot 01$ to $1 \cdot 31)$ & $1 \cdot 17(1.01$ to 1.33$)$ & $1.26(1.08$ to 1.43$)$ \\
\hline $\begin{array}{l}\text { Circulatory deaths: } \\
\text { Lag } 1 \text { day }\end{array}$ & $1.05(0.95$ to 1.14$)$ & $1.08(0.99$ to 1.18$)$ & $1.11(1.01$ to 1.22$)$ \\
\hline \multicolumn{4}{|c|}{$232(1.01+1.60)$} \\
\hline $\begin{array}{l}\text { Same day } \\
\text { Lag } 1 \text { day }\end{array}$ & $\begin{array}{l}1.18(0.91 \text { to } 1.47) \\
1.12(0.91 \text { to } 1.47)\end{array}$ & $\begin{array}{l}1.33(1.01 \text { to } 1.62) \\
1.23(1.01 \text { to } 1.62)\end{array}$ & $1.45(1.10$ to 1.77$)$ \\
\hline \multicolumn{4}{|l|}{ All causes mortality: } \\
\hline & $1 \cdot 04(0.98$ to $1 \cdot 10)$ & $1.07(1.01$ to $1 \cdot 14)$ & $1 \cdot 10(1.02$ to $1 \cdot 16)$ \\
\hline
\end{tabular}

Relative risk is calculated with values for health outcomes predicted in the model by comparing absolute risk on all days in excess of the threshold with average absolute risk over the whole two year period.

the effects of lagged temperature in the sensitivity analysis, and also showed that a significant association between hospital admissions for respiratory disease and $\mathrm{PM}_{10}$ is present in 26 of 30 ranked and essentially isothermal groups. This suggests that the association described is not due to confounding effects of temperature. However, it is possible that health outcomes relate not just to these, but to factors such as diurnal temperature swing, or to longer term moving mean temperatures, and the optimum method of adjusting for confounding meteorological factors in analyses of this kind requires further work. Although temperature can show a non-linear or $U$ shaped association with mortality and hospital admissions, this was not found in our data, and the use of a linear temperature term was valid.

Gaseous pollutants may also show significant association with health outcomes. However, it is difficult to determine this because they vary closely with particulate concentrations. Multiple regression analysis can help to
Figure 5 Relative risk for $P M_{10}$ excursions for hospital admissions for all respiratory conditions, with a $P M_{10}$ model of the moving mean of the past three days.

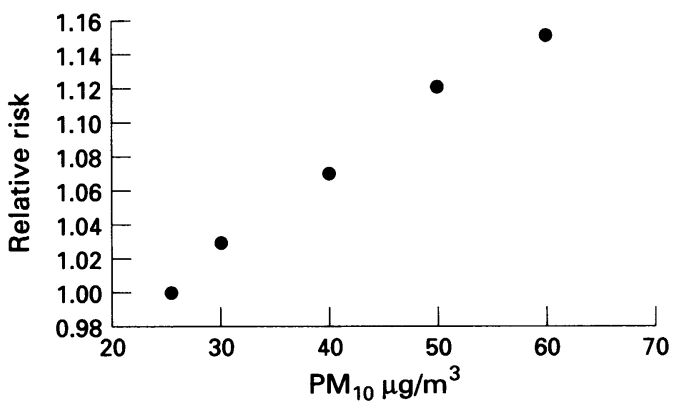

Figure 6 Relative risk for all causes mortality for $P M_{10}$ values above various thresholds with a $P M_{10}$ model with a one day lag. find the associations when variables are independent, but in reality effects of individual pollutants are not independent of each other. A synoptic climatological approach may help to determine covarying physicochemical atmospheric characteristics, and may be a more appropriate method of finding the contributory effects of different pollutant mixtures than multiple regression analysis. This paper considers $\mathrm{PM}_{10}$ in isolation, and further work is required to determine the role of different covarying pollutant and pollutant-weather combinations.

The estimates of health effects that might have been attributed to $\mathrm{PM}_{10}$ over the two year period of the study make several key assumptions: we have to assume that the effects are causal, that they are due either to $\mathrm{PM}_{10}$ alone or acting in conjunction with other pollutants, and that on each of the days when $\mathbf{P M}_{10}$ thresholds were exceeded, the concentrations could have been lowered to the threshold value. Nevertheless they represent an attempt, albeit crude, to look at the level of health effects that might be attributed to $\mathrm{PM}_{10}$ pollution over the two year period in question, taking into account both the number of days on which various thresholds were exceeded, and the amount by which those thresholds were exceeded in a real city situation. This is not to say that other pollutants might not also have additional independent effects, nor that all the effects found here are attributable solely to $\mathrm{PM}_{10}$

The estimated size of health effect is similar to that found in other studies, mainly from the United States. We estimate that an excursion of $\mathrm{PM}_{10}$ of $10 \mu \mathrm{g} / \mathrm{m}^{3}$ would result in a $2.4 \%$ increase in all respiratory admissions and a $1.1 \%$ increase in all causes mortality. In a population of 1 million, this would be only $0 \cdot 3$ extra deaths and 0.5 extra hospital admissions for respiratory disease. Estimates for certain specific causes of death and hospital admission were higher, but associated with wider confidence intervals.

There have been several recent reviews of the literature on acute mortality and particulates, three of which review studies on the 
Table 8 Number ${ }^{*} \%$ of all admissions or deaths for different health outcomes that might be avoided if $P M_{10}$ changes above different thresholds were prevented

\begin{tabular}{|c|c|c|c|c|}
\hline \multirow{2}{*}{$\begin{array}{l}\text { Health outcome indicator and } P M_{10} \\
\text { model used }\end{array}$} & \multicolumn{4}{|c|}{ Events saved per year in a population of one million if $P M_{10}$ did not exceed } \\
\hline & $40 \mu g / m^{3}$ & $50 \mu g / m^{3}$ & $60 \mu g / m^{3}$ & $70 \mu g / m^{3}$ \\
\hline \multicolumn{5}{|l|}{ All respiratory admissions: } \\
\hline & $42.6(0.53)$ & $21 \cdot 1(0 \cdot 26)$ & $9 \cdot 8(0 \cdot 12)$ & $4.9(0.06)$ \\
\hline Moving mean of past 3 days & $31.6(0.39)$ & $13.4(0 \cdot 18)$ & $5.7(0.07)$ & $2.9(0.04)$ \\
\hline \multicolumn{5}{|l|}{ Asthma admissions: } \\
\hline Lag 2 day & $17 \cdot 3(0 \cdot 75)$ & $8 \cdot 6(0 \cdot 37)$ & $4 \cdot 0(0 \cdot 17)$ & $2.0(0.09)$ \\
\hline Moving mean of past 3 days & $13.5(0.59)$ & $5 \cdot 7(0 \cdot 25)$ & $2 \cdot 4(0 \cdot 11)$ & $1 \cdot 2(0.05)$ \\
\hline \multicolumn{5}{|l|}{ Bronchitis admissions: } \\
\hline Same day & $8 \cdot 3(0.94)$ & $4 \cdot 1(0 \cdot 46)$ & $1.9(0 \cdot 21)$ & $1 \cdot 0(0 \cdot 11)$ \\
\hline \multicolumn{5}{|l|}{ Pneumonia admissions: } \\
\hline Lag 3 day & $15 \cdot 1(1 \cdot 22)$ & $7 \cdot 5(0 \cdot 60)$ & $3.5(0.28)$ & $1 \cdot 7(0 \cdot 14)$ \\
\hline Moving mean of past 3 days & $10 \cdot 5(0 \cdot 85)$ & $4.4(0 \cdot 36)$ & $1.9(0 \cdot 15)$ & $1.0(0.08)$ \\
\hline \multicolumn{5}{|l|}{ Cerebrovascular admissions: } \\
\hline Same day & $11 \cdot 1(0 \cdot 45)$ & $5 \cdot 5(0 \cdot 22)$ & $2 \cdot 5(0 \cdot 1)$ & $1.3(0.05)$ \\
\hline \multicolumn{5}{|l|}{ Circulatory deaths: } \\
\hline Lag 1 day & $58 \cdot 3(1 \cdot 33)$ & $38.9(0.89)$ & $21 \cdot 2(0 \cdot 37)$ & $12.5(0.29)$ \\
\hline \multicolumn{5}{|l|}{ COPD deaths: } \\
\hline Same day & $20 \cdot 3(4 \cdot 00)$ & $13 \cdot 5(2 \cdot 67)$ & $7 \cdot 4(1 \cdot 46)$ & $4 \cdot 4(0 \cdot 86)$ \\
\hline Lag 1 day & $19 \cdot 1(3 \cdot 77)$ & $12 \cdot 8(2 \cdot 51)$ & $7.0(1.37)$ & $4 \cdot 1(0 \cdot 81)$ \\
\hline \multicolumn{5}{|l|}{ All causes mortality: } \\
\hline Lag 1 day & $94 \cdot 2(0 \cdot 87)$ & $62.8(0.58)$ & $64 \cdot 3(0 \cdot 32)$ & $20 \cdot 2(0 \cdot 19)$ \\
\hline
\end{tabular}

Calculated with values predicted by a model.

* Numbers refer to deaths or admissions saved in a population of 1 million in one year.

health effects of $\mathrm{PM}_{10} \cdot{ }^{101124}$ There is now a strong consensus that there is a significant and consistent association between mortality and $\mathrm{PM}_{10}$. Although all studies are different in their location, and thus differ in background concentrations of particulates, sources of particulates, and in their approach to confounding factors, they suggest an increase of $1 \%$ in all causes mortality for every $10 \mu \mathrm{g} / \mathrm{m}^{3}$ increase in $\mathrm{PM}_{10}$. This study could not answer the question whether the observed short term increases in mortality represent early death in seriously ill people or signify an increase in overall mortalities.

There is greater variation in studies of acute hospital admissions or attendances and ambient concentrations of $\mathrm{PM}_{10}$, with some recent studies from Europe reporting no association. However, these studies on acute health service use have been reviewed recently, again suggesting a consistent association between hospital use for acute respiratory conditions and ambient $\mathrm{PM}_{10} \cdot{ }^{25}$ Our finding of a $2 \cdot 4 \%$ increase in all respiratory admissions for a $10 \mu \mathrm{g} / \mathrm{m}^{3}$ increase in $\mathrm{PM}_{10}$ is consistent with the findings of this review.

The consistency of published work and of our findings suggest that they are not spurious or due to confounding. Instead our work provides evidence that the relations found in the United States are also present in one city in the United Kingdom, even under different climatic conditions and with different sources of $\mathrm{PM}_{10}$.

There is an important and unexplained difference between our work and that from the United States - the absence of an association between admissions and deaths for ischaemic heart disease and $\mathrm{PM}_{10}$. The reason for this is unknown. It may explain why our estimates of health benefits are relatively small, as they exclude any effect on ischaemic heart disease.

We were unable to study the effects in population subgroups, such as children and elderly people, in this study because small daily numbers of health outcome events preclude separate analysis of subgroups. Some studies suggest that elderly people may be at greater risk. ${ }^{58} \mathrm{We}$ were also unable to look at the potential importance of different components of $\mathrm{PM}_{10}$ on health outcomes. Some studies suggest that finer particles $\left(\mathbf{P M}_{2 \cdot 5}\right)$ have greater effect, and others that acid aerosols show the strongest association with health outcomes. ${ }^{141626}$ The question as to whether there are sensitive subgroups within the population, and which components of $\mathrm{PM}_{10}$ are most closely associated with health effects require further study in the United Kingdom. The results from this study also require confirmation from other cities in the United Kingdom.

Although we have shown significant associations between acute health outcomes and ambient $\mathbf{P M}_{10}$, the size of this effect is small, representing between $10 \%$ and $77 \%$ increments in risk on days when $\mathbf{P M}_{10}$ exceeds $70 \mu \mathrm{g} / \mathrm{m}^{3}$. Translating our findings back to find the potential reduction in hospital admissions and deaths if excursions above various thresholds could be prevented shows a limited impact on these health outcomes. If we could prevent $\mathrm{PM}_{10}$ exceeding $70 \mu \mathrm{g} / \mathrm{m}^{3}$ (the 1987 World Health Organisation air quality guideline for thoracic particulates ${ }^{27}$ ), this would result in $<1 \%$ reduction in all health outcomes that we studied, although the potential impacts of reducing $\mathrm{PM}_{10}$ to $<60 \mu \mathrm{g} / \mathrm{m}^{3}$ and $<50 \mu \mathrm{g} / \mathrm{m}^{3}$ are greater.

However, there are difficulties in using health effect information such as this in finding where air quality guidelines should be set, particularly when the relation between exposure and outcome does not show a threshold of effect. For ozone, a threshold of effect can be agreed on which eases the task of recommending a standard. For particles the problem is more difficult as the relation is that of a dose response curve with no obvious threshold. Intuitively, there must be a threshold of effect, but is it likely that such a threshold will vary between people in a population according to personal exposure and susceptibility- such as those with more severe asthma. Neither of these two factors have been taken into account by our study or any other study of this type. What effect these factors would have in affect- 
ing estimations of the overall effect of $\mathrm{PM}_{4}$ on health needs to be considered. However, whatever the contributory factors might be, the dose response relation for the population will be the sum of the individual dose response curves. If an air quality standard is based on health effects and on potential health savings at certain thresholds, then it is inevitable that a degree of morbidity will have to be accepted whatever the standard selected. Indeed, the degree of morbidity will vary from urban to rural areas and between cities because of differences in air quality and meteorological conditions. For example, estimates based on the Birmingham data may not apply to Belfast, where burning fossil fuels remains a major source of air pollution

It should be noted that our estimates of health impact are conservative, and based on the assumption that the only impact of control measures is to reduce $\mathrm{PM}_{1,1}$ to just below the chosen threshold on days when it would otherwise have exceeded that threshold. In reality, such control measures are likely to reduce the number of days on which lower thresholds are exceeded, as well as reducing mean $\mathrm{PM}_{1, \ldots}$, so producing greater health benefits. Also, the estimates are specific to Birmingham, where values in excess of $70 \mu \mathrm{g} / \mathrm{m}^{3}$ occur only rarely in comparison with some other parts of the United Kingdom. Nevertheless, the estimate of health effect from this study contradicts the popular view that air pollution is to blame for most respiratory disease. There is a significant association between $\mathrm{PM}_{10}$ and acute health effects in the United Kingdom, but at ambient United Kingdom concentrations, this effect is small, and accounts for few of the deaths from and hospital admissions for acute respiratory and circulatory causes.

\section{Conclusion}

Ambient outdoor concentrations of $\mathrm{PM}_{11}$ in the United Kingdom show significant associations with several indicators of acute health effects. These associations are similar to and consistent with other studies. However, the size of public health effect is relatively small, values $<70 \mu \mathrm{g} / \mathrm{m}^{3}$ accounting for under $1 \%$ of all deaths or hospital admissions for respiratory diseases over a two year period.

This study was funded by the Department of the Environment, project number EPG 1/3/42. We thank Mrs Andrea Thomas at the West Midlands Regional Health Authority for assistance in obtaining the health outcomes data.

1 Schwartz J. Particulate air pollution and daily mortality in Detroit. Environ Res 1991;56:204-13.
2 Fairley D. The relationship of daily mortality to suspended particulates in Santa Clara County, 1980 6. Environ $R$ os $1990 ; 89: 159-213$

3 Schwartz J, Dockery DW. Particulate air pollution and daily mortality in Steubenville, Ohio. Am $\mathcal{F}$ Epidemiol $1992 ; 135: 12-9$

4 Schwartz J, Dockery DW. Increased mortality in Philadelphia associated with daily air pollution concentrations. Am Rev Respir Dis 1992;145:600 4

5 Pope CA, Schwartz J, Ransom MR. 1)aily mortality and $\mathrm{PM}_{1}$ pollution in Utah valley. Arch Environ Health 1992 47:211 7

6 Schwartz J. Particulate air pollution and daily mortality in Cincinatti, Ohio. Environ Health Perspect 1994;102 1869.

7 Schwartz J. Air pollution and daily mortality in Birmingham, Alabama. Am $f$ Epidemiol 1993;137: $1136-47$

$\&$ Pope CA, Dockery DW, Schwart\% J. Review of epidemio ogical evidence of health effects of air pollution. Inhalation Toxicol 1995;7:1 18.

9 Dockery DW, Pope CA. Acute respiratory effects of particulate air pollution. Ann Rer Public Hialth 1994;15: $107-32$.

10 Pope CA. Respiratory disease associated with community air pollution and a steel mill, Utah Vallev. $A m \mathcal{F}$ Public Health 1989;79:623-8.

11 Pope CA. Respiratory hospital admissions associated with PM pollution in Utah, Salt Lake and Cache Valleys. PM pollution in Utah, Salt Lake
Arch Environ Health 1991:46:90-7.

12 Thurston GD, Ito K, Hayes CG, Bates DV, Lippmann M Respiratory hospital admissions and summertime haze air pollution in Toronto, Ontario: consideration of the rol of acid aerosols. Environ Res 1994;65:27190.

13 Lipfert FW, Hammerstrom T. Temporal patterns in ai pollution and hospital admissions. Fuviron Rcs 1992 59:374-99.

14 Thurston GD, Ito K, Kinney PL, Lippmann M. A multiyear study of air pollution and respiratory hospital admissions in three New York State metropolitan areas: results for 1988 and 1989 summers. Foumal of Exposur. Analysis for 1988 and 1989 summers. Fournal of Exposur

15 Schwartz J. Air pollution and hospital admissions for the elderly in Birmingham, Alabama. Am f Epidimiol 1994 139:589.98

16 Schwartz J, Slater D, L arson TV, Pierson WE, Koenig JQ Particulate air pollution and hospital emergency room visits for asthma in Seattle. Am Ret Respir Dis 1992 $147: 826-31$

17 St Leger S, ed. The APHEA Project: short term effects of air pollution on health: a European approach using epidemiological time series data. 7 Epidemiol Community Hialth 1996;50:1 79 .

18 Zmirou D, Barumandzadeh $\mathrm{T}$, Balducci F, Ritter P, I aham G, Ghilardi J-P. Short term effects of air pollution on mortality in the city of Lyon, France, 1985-90. Epidemiol Community' Health 1996;50:30) 5 .

19 1)ab W, Medina S, Quenel P, Le Mollec Y, Le Tertre A Thelot B, et al. Short term respiratory health effects of ambient air pollution: results of the APHEA project in Paris. F Epidemiol Community Health 1996;50:42 6

20 Spix C, Wichmann HE. Daily mortality and air pollutants findings from Koln, Germany. 7 Epidemiol Communit Health 1996;50:52-8

21 Walters S, Griffiths RK, Ayres JG. Temporal association between hospital admissions for asthma in Birmingham and ambient levels of sulphur dioxide and smoke. Thorax 1994;49:133-40.

22 Anderson HR, Ponce de Leon A, Bland JM, Bower JS, Strachan DP. Air pollution and daily mortality in london 1987-92. BMF 1996;312:665 9.

23 Ponce de Leon A, Anderson HR, Bland JM, Strachan DP, Bower J. Effects of air pollution on daily hospital admis sions for respiratory disease in London between 1987-88 and 1991-2. F Epidemiol Community Health 1996;52 63.70 .

24 Ostro B. The association of air pollution and mortality examining the case for inference. Arch Environ Health 1993;48:336-42

25 Lipfert FW. A critical review of the association between demands for hospital services and air pollution. Enciron demands for hospital services and air pollut
Health Perspect 1993:101 (suppl 2);229 68.

26 Dockery DW, Schwartz J, Spengler J. Air pollution and daily mortality: associations with particulates and acic aerosols. Environ Res 1992:59.362 particu

27 World Health Organisation. Air Quality Guidelines for the Europian Region. Copenhagen: WHO, 1987. 